\title{
Prevalence and Risk Factors of Maternal Anxiety in Late Pregnancy in China
}

\author{
Yu-ting Kang ${ }^{1,+}$, Yan Yao ${ }^{2,+}$, Jing Dou ${ }^{2}$, Xin Guo ${ }^{2}$, Shu-yue Li ${ }^{3}$, Cai-ning Zhao ${ }^{1}$, \\ Hong-zhi Han ${ }^{4}$ and $\mathrm{Bo} \mathrm{Li}^{2, *}$ \\ 1 School of Public Health, Jilin University, Changchun 130021, China; 18204319702@163.com (Y.-t.K.); \\ zhaocn2711@mails.jlu.edu.cn (C.-n.Z.) \\ 2 Department of Epidemiology and Biostatistics, School of Public Health, Jilin University, Changchun 130021, \\ China; yaoyan@jlu.edu.cn (Y.Y.); 13526627874@163.com (J.D.); gggxxxfly@163.com (X.G.) \\ 3 Center for Nursing Service, Changchun Maternity Hospital, Changchun 130021, China; kelly11637@sina.com \\ 4 Editorial Office of Journal of Jilin University, Medicine Edition, Changchun, Jilin 130012, China; \\ hanhz@jlu.edu.cn \\ * Correspondence: li_bo@jlu.edu.cn; Tel.: +86-8561-9451 \\ $\dagger$ These authors contributed equally to this work.
}

Academic Editor: Paul B. Tchounwou

Received: 10 March 2016; Accepted: 23 April 2016; Published: 4 May 2016

\begin{abstract}
Objective: A large number of studies have shown the adverse neonatal outcomes of maternal psychological ill health. Given the potentially high prevalence of antenatal anxiety and few studies performed among Chinese people, the authors wanted to investigate the prevalence of antenatal anxiety and associated factors among pregnant women and to provide scientific basis to reduce prenatal anxiety effectively. Methods: A cross-sectional study was carried out at the Changchun Gynecology and Obstetrics Hospital from January 2015 to march 2015, with 467 participants of at least 38 weeks' gestation enrolled. Antenatal anxiety was measured using the Self-Rating Anxiety Scale (SAS). $\chi^{2}$ test and logistic regression analysis were performed to evaluate the association of related factors of antenatal anxiety. Results: Among the 467 participants, the prevalence of antenatal anxiety was $20.6 \%$ (96 of 467). After adjustment for women's socio-demographic characteristics (e.g., area, age, household income), multivariate logistical regression analysis revealed that antenatal anxiety showed significant relationship with education level lower than middle school (years $\leqslant 9$ ), expected natural delivery, anemia during pregnancy, pregnancy-induced hypertension syndrome, disharmony in family relationship and life satisfaction. Conclusions: It is important to prevent or reduce antenatal anxiety from occurring by improving the health status of pregnant women and strengthening prenatal-related education and mental intervention.
\end{abstract}

Keywords: antenatal anxiety; mental health; nursing; risk factors; cross-sectional study; chinese women

\section{Introduction}

As the modern medical model develops, psychological health has been increasingly given more attention. Previous researches have shown a high prevalence of psychiatric illness in pregnant women [1,2], not only in the developed countries, but also in developing countries such as Turkey [3]. Furthermore, a large body of research exists on the adverse outcomes of maternal psychological ill health $[4,5]$, most notably depression and anxiety during pregnancy. For example, psychiatric illness during pregnancy is considered to contribute to prematurity, low birth weight and obstetric complications [6,7].

Antenatal anxiety, as a common form of psychiatric illness, is a reflection of stress response [8], which occurs when personal well-being is threatened during pregnancy. Antenatal anxiety 
has been thought to be related to attention-deficit/hyperactivity disorder in children born to women who experience such antenatal anxiety [9-12]. It is believed that change in maternal hypothalamic-pituitary-adrenal (HPA) axis activity and fetal over exposure to glucocorticoids are potential pathogenetic factors in these adverse outcomes [13,14]. Findings from some studies indicated that anxiety is more common during pregnancy than depression and often co-morbid with depression, even related to the occurrence of postnatal depression across many countries $[7,15,16]$. Studies have examined the prevalence and its associated factors of postnatal depression [17], whereas only a few studies have explored the prevalence of anxiety in pregnancy.

Antenatal anxiety is believed to be a psycho-biological process, which means that it is also influenced by complex biological systems, particularly the endocrine system. The fluctuation of estrogen and progesterone may also induce anxiety among pregnant women [18]. Regarding the fact that endocrine system change largely, it is possible that antenatal anxiety rise as birth approaches [19].

In Chinese culture, there exists a widespread gender preference for male progeny. For a long time, this preference led to a high number of sex-selected abortions of female fetuses, contributing to an unequal male-to-female ratio. Today, fetal sex determination is forbidden, which may increase the level of anxiety in pregnant women who have a preference for a male child, because of the uncertainty of the fetal sex. A study in Bangladesh reported a $29 \%$ high prevalence of antenatal anxiety regarding the gender sensitivities in their country [20]. Similarly, there may be a potentially high prevalence of anxiety among Chinese women. While there are studies on postpartum depression and gender preference [21], little research is available on either the prevalence or factors associated with antenatal anxiety in China. A study in Hong Kong showed a negative relationship between feelings of control during labour and maternal anxiety. However, given the economic and cultural differences between Hong Kong and mainland China, it is difficult to extrapolate the findings of the study to our region of China [22]. Furthermore, the prevalence of antenatal anxiety varies widely from $9.1 \%$ to $59.5 \%$ assessed by different scales [19,23-25], scarce work has been done to examine the prevalence in China.

Thus, given the potential high prevalence and its possible adverse effects of antenatal anxiety [26], the authors wanted to determine the prevalence of prenatal anxiety in Changchun, Jilin Province, Northeast China, and to understand the associated risk factors during antepartum hospitalization. We hope that by raising the awareness of maternal prenatal anxiety among health care professionals and caregivers, mothers will be screened early in their pregnancy and offered personalized services for their psychological health in order to reduce, distress and improve pregnancy outcomes [27].

\section{Experimental Section}

\subsection{Study Design}

A cross-sectional study was conducted at Changchun Maternity Hospital in the Jilin Province of China from January to March in 2015. Since we could not ensure random sampling due to lack of resources, we used a sampling group of hospitalized pregnant women awaiting delivery. The inclusion criteria included the following: Chinese nationality, a gestation of at least 38 weeks, a pregnancy without any complications, such as twins or known congenital anomalies, and the ability to complete the survey. Afterwards, face-to-face interviews with participants before delivery were carried out in private by trained research assistants using a structured questionnaire. After the participants were informed of the objectives of the study, those who were willing to participate in the survey signed written informed consent. Finally, we enrolled a sample group of 476 pregnant women who met the criteria for antenatal anxiety. We've gained the permission from the Ethics Committee of Public Health, Jilin University and were in accordance with the ethical standards (approval code: 2014-1128).

\subsection{Data Collection}

The potential risk factors of antenatal anxiety were selected, based on our literature search. 


\subsubsection{Demographics Questionnaire}

The demographics questionnaire was developed specially for the study. The following demographic variables were collected: age, height, pre-pregnancy and late pregnancy weight, household income per month, education level in three level bands, occupation, marital relationship, type of delivery, and information on current health status such as pregnancy-induced hypertension syndrome and prenatal anemia. Social supports and sleep quality were also obtained in the study.

\subsubsection{Age Groups}

In China, most women marry and deliver a baby before they are 30 years of age. If a woman does not have a child after reaching 30 years of age, she and her partner will very likely experience pressure to do so from both parents and friends, so we have set 30 years of age as the limit to explore whether age can influence the anxiety level of pregnant women. Being $\geqslant 35$ years old is believed to make a high risk pregnancy more likely, which can lead to pregnancy complications such as pregnancy-induced hypertension, and can increase the chances that the baby will suffer birth defects. According to the inclination of most Chinese women and based on clinical significance, we divided participants into three age groups.

\subsubsection{Personality}

The Big Five personality traits are strongly related to mental health. A study from Kaplan agreed that openness, agreeableness, and conscientiousness are intermingled [28], so we wanted to use more concise and representative personality traits in our paper. The personality subgroups in our study are "extraversion", "neuroticism" and "agreeableness".

\subsubsection{Morning Sickness}

The present study suggested that morning sickness and anxiety disorders are frequently observed among pregnant women [29]. Our hypothesis was that there is a potential association between psychiatric disorders and morning sickness. The recorded severity of the morning sickness in our study was based on self-reporting by the pregnant women. If a woman reported morning sickness that lasted for a long period of time and was more serious, she was placed into a "serious" subgroup. If a woman reported morning sickness that lasted for a shorter period of time and was less severe, she was placed into a "light" subgroup. The other women who reported morning sickness between "serious" and "light" were defined as "medium".

\subsubsection{Postpartum Care and Premarital Examination}

In China, if pregnant women deliver babies, parents or maternity matrons usually take care of them and their babies. This phenomenon is called "postpartum care". We think it is an important social support and also may be an important factor in antenatal anxiety. A premarital examination is the physical examination prior to marriage, which includes testing for inherited diseases and venereal diseases. Our hypothesis is that if a woman knows that she and her partner do not have any of those problems, she will be confident in regard to her own and her baby's health. This examination may decrease the anxiety of pregnant women and may make them less likely to suffer antenatal anxiety.

\subsubsection{Antenatal Anxiety}

The Self-Rating Anxiety Scale (SAS) developed to assess adult anxiety, has demonstrated adequate validity and acceptable reliability in a previous study [30]. The SAS includes 20 items using 4-point response options ranging from 1 (never) to 4 (very often) to capture symptoms of antenatal anxiety. The responses are used to give a total score that can range from 20 to 80 and then the standard score equal to the integral part of the figure of total score multiplied by 1.25 . To identify women with antenatal anxiety, a standard score $\geqslant 50$ has been recommended [31], with higher scores 
indicating higher levels of anxiety. To measure symptoms of antenatal anxiety in current study, the participants were required to answer the frequency of each items over the past week in SAS, which the authors believe to be a good reflection on their attitudes before delivery and can be deemed as a dependent variable.

\subsubsection{Life Satisfaction}

Life satisfaction was assessed by the Satisfaction With Life Scale (SWLS) in the study. The SWLS, developed originally in 1985, includes only five items; however, it has been proven to be valid and reliable in previous studies $[32,33]$ and has been used widely across many countries, including China [34]. A seven-point response option ranging from 1 (strongly disagree) to 7 (strongly agree) was used to examine an individual's satisfaction with their life. The responses were added together to give a total score, ranging from 5 to 35 . On this scale, 20 scores represented the neutral attitude. Scores between 5 and 9 represented extreme dissatisfaction with life, scores between 15 and 19 represented slight dissatisfaction with life, scores between 21 and 25 represented slight satisfaction with life, and scores ranging from 31 to 35 represented extreme satisfaction with life [35]. However, in our study, we combined groups representing extreme dissatisfaction, dissatisfaction, slight dissatisfaction, neutrality, and slight satisfaction; that is, scores ranging from 5 to 25 were considered to be dissatisfied with life. After transition, life satisfaction was seen as independent for analysis.

\subsection{Data Analysis}

Data were entered into IBM SPSS statistical software program, version 19.0 (International Business Machines Corp., Armonk, NY, USA), and were then analyzed after being checked and corrected for any errors, including continuous variables (age, anxiety score, life satisfaction score) and categorical variables (area, income level, education level, occupation, personal character, experience of support from the partner and family, expected birth mode, postpartum care, premarital examination, anemia before or during pregnancy, gestational diabetes, calf cramps, pregnancy-induced hypertension, sleep deprivation, morning sickness). Based on Chinese cultural attitudes and the available literature $[21,36]$, we converted continuous variables into categorical variables to achieve better analysis (details Table 1). Frequency distributions and descriptive statistics for major demographic variables were computed. The $\chi^{2}$ test was used to analyze the significant associations between variables and antenatal anxiety. Logistic regression is used to identify significant variables by removing confounding factors. We posit that it is more accurate and acceptable to include those potentially revealing variates $(p \leqslant 0.20)$ for use in adjustments [37]. Therefore, the variables were included in the bivariate logistic regression model to determine their independent contribution to antenatal anxiety and whether they had a significant association $(p \leqslant 0.20)$ according to the $\chi^{2}$ test or whether they were deemed important clinically even without statistical significance, as would be true in the case of gestational diabetes mellitus, for example. To estimate the strength of associations, odds ratios (OR) and $95 \%$ confidence intervals $(C I)$ were presented for all variables in bivariate regression models. An $\alpha$ level of 0.05 was used for statistical tests. 
Table 1. Socio-demographic characteristics and health states of the total participants $(n=467)$.

\begin{tabular}{|c|c|c|c|c|}
\hline \multirow[t]{2}{*}{ Characteristics } & $\begin{array}{c}\text { No Antenatal } \\
\text { Anxiety } n=371\end{array}$ & $\begin{array}{c}\text { Antenatal } \\
\text { Anxiety } n=96\end{array}$ & \multirow[t]{2}{*}{$x^{2}$} & \multirow[t]{2}{*}{$p$ Value } \\
\hline & n $(\%)$ & n (\%) & & \\
\hline \multicolumn{5}{|l|}{ Area } \\
\hline Urban & $203(54.7)$ & $49(51.0)$ & 3.723 & 0.155 \\
\hline County & $113(30.5)$ & $25(26.0)$ & & \\
\hline Rural & $55(14.8)$ & $22(22.9)$ & & \\
\hline \multicolumn{5}{|l|}{ Age (years) } \\
\hline$<30$ & $240(64.7)$ & $69(71.9)$ & 2.571 & 0.277 \\
\hline $30-35$ & $95(25.6)$ & $22(22.9)$ & & \\
\hline$\geqslant 35$ & $36(9.7)$ & $5(5.2)$ & & \\
\hline \multicolumn{5}{|l|}{ Household Income (¥) } \\
\hline$<3000$ & $167(45.0)$ & $39(40.6)$ & 0.600 & 0.440 \\
\hline$\geqslant 3000$ & $204(55.0)$ & $57(59.4)$ & & \\
\hline \multicolumn{5}{|l|}{ Educational Level } \\
\hline \multirow{2}{*}{$\begin{array}{l}\text { Middle School or Below } \\
\text { High School or Technical } \\
\text { Secondary School }\end{array}$} & $42(11.3)$ & $24(25.0)$ & 13.705 & 0.001 \\
\hline & $179(48.2)$ & $46(47.9)$ & & \\
\hline College or Higher & $150(40.4)$ & $26(27.1)$ & & \\
\hline \multicolumn{5}{|l|}{ Job } \\
\hline Muscular Work & $172(46.4)$ & $43(46.9)$ & 0.767 & 0.681 \\
\hline Mental Work & 159 (42.9) & $45(46.9)$ & & \\
\hline Other $^{a}$ & $40(10.8)$ & $8(8.3)$ & & \\
\hline \multicolumn{5}{|l|}{ Personality } \\
\hline Extraversion & $167(45.0)$ & $40(41.7)$ & 1.250 & 0.535 \\
\hline Neuroticism & $70(18.9)$ & $23(24.0)$ & & \\
\hline Agreeableness & $134(36.1)$ & $33(34.4)$ & & \\
\hline \multicolumn{5}{|l|}{ Conjugal Relationship } \\
\hline Harmony & $330(88.9)$ & $64(66.7)$ & 28.712 & $<0.001$ \\
\hline Disharmony & $41(11.1)$ & $32(33.3)$ & & \\
\hline \multicolumn{5}{|l|}{ Family Relationship } \\
\hline Harmony & $329(88.7)$ & $60(62.5)$ & 37.569 & $<0.001$ \\
\hline Disharmony & $42(11.3)$ & $36(37.5)$ & & \\
\hline \multicolumn{5}{|l|}{ Expected Birth Mode } \\
\hline Natural Delivery & $136(36.7)$ & $48(50.0)$ & 5.686 & 0.017 \\
\hline Caesarean Sections & $235(63.3)$ & $48(50.0)$ & & \\
\hline \multicolumn{5}{|l|}{ Postpartum Care } \\
\hline Yes & $281(75.7)$ & $68(70.8)$ & 0.973 & 0.324 \\
\hline No & $90(24.3)$ & $28(29.2)$ & & \\
\hline \multicolumn{5}{|l|}{ Premarital Examination } \\
\hline Yes & $207(55.8)$ & $50(52.1)$ & 0.425 & 0.515 \\
\hline No & $164(44.2)$ & $46(47.9)$ & & \\
\hline \multicolumn{5}{|l|}{ Anemia Before Pregnancy } \\
\hline Yes & $17(4.6)$ & $8(8.3)$ & 2.118 & 0.146 \\
\hline No & $354(95.4)$ & $88(91.7)$ & & \\
\hline \multicolumn{5}{|l|}{ Anemia During Pregnancy } \\
\hline Yes & $329(88.7)$ & $42(11.3)$ & 2.819 & 0.093 \\
\hline No & $79(82.3)$ & $17(17.7)$ & & \\
\hline \multicolumn{5}{|l|}{ Gestational Diabetes Mellitus } \\
\hline Yes & $17(4.6)$ & $7(7.3)$ & 0.660 & 0.417 \\
\hline No & $354(95.4)$ & $89(92.7)$ & & \\
\hline
\end{tabular}


Table 1. Cont.

\begin{tabular}{|c|c|c|c|c|}
\hline \multirow{2}{*}{ Characteristics } & $\begin{array}{c}\text { No Antenatal } \\
\text { Anxiety } n=371\end{array}$ & $\begin{array}{c}\text { Antenatal } \\
\text { Anxiety } n=96\end{array}$ & \multirow{2}{*}{$x^{2}$} & \multirow[t]{2}{*}{$p$ Value } \\
\hline & n (\%) & n $(\%)$ & & \\
\hline \multicolumn{5}{|l|}{ Calf Cramps } \\
\hline Yes & $97(26.1)$ & $30(31.3)$ & 1.004 & 0.316 \\
\hline No & $274(73.9)$ & $66(68.8)$ & & \\
\hline \multicolumn{5}{|c|}{ Pregnancy-Induced Hypertension } \\
\hline Yes & $12(3.2)$ & $13(13.5)$ & 15.991 & $<0.001$ \\
\hline No & $359(96.8)$ & $83(86.5)$ & & \\
\hline \multicolumn{5}{|l|}{ Sleep Deprivation } \\
\hline Worse & $40(10.8)$ & $5(5.2)$ & 6.194 & 0.045 \\
\hline The Same & $263(70.9)$ & $80(83.3)$ & & \\
\hline Better & $68(18.3)$ & $11(11.5)$ & & \\
\hline \multicolumn{5}{|l|}{ Morning Sickness } \\
\hline Serious & $54(14.6)$ & $22(22.9)$ & 5.543 & 0.063 \\
\hline Medium & $229(61.7)$ & $59(61.5)$ & & \\
\hline Light & $88(23.7)$ & $16(15.6)$ & & \\
\hline \multicolumn{5}{|l|}{ Life Satisfaction } \\
\hline Yes & $340(91.6)$ & $58(60.4)$ & 59.062 & $<0.001$ \\
\hline No & $31(8.4)$ & $38(39.6)$ & & \\
\hline
\end{tabular}

${ }^{a}$ Refers to occupations that could not be classified such as, housewife, massage therapist, etc.

\section{Results}

\subsection{Participants}

Because we conducted face-to-face interviews in our study, trained nurses collected the questionnaires after completing the interviews, so there are no missing data. The mean age was 28.9 years (standard deviation $(S D)=4.3$ ). In our study, the majority of pregnant women reported high-school or technical secondary school degree $(48.2 \%)$ followed by college or above degree $(37.3 \%)$ and middle school or below degree (14.1\%). Occupations involving mental labour (45.0\%), including administration, medicine, education, and recreation and sports were most common, followed by physical labour $(43.6 \%)$, including agriculture and livestock, service industry, and others $(11.4 \%)$, which included occupations that could not be classified such as housewife, massage therapist, etc. Most women $(54.0 \%)$ were from urban areas; $29.6 \%$ came from the surrounding county, and $16.5 \%$ were from rural areas. Furthermore, $44.1 \%$ of average household income per month was below 3000 Chinese yuan (\$471), which is the average household income per month in Jilin, China, according to National Bureau of Statistics of the People's Republic of China.

\subsection{Prevalence of Antenatal Anxiety}

Slight and moderate anxiety was reported by $18.4 \%$ and $2.1 \%$ women respectively giving an overall prevalence of antenatal anxiety of $20.6 \%$ (96 of $467 ; 95 \%$ CI $17.0 \%-24.5 \%$ ). No severe antenatal anxiety was found in the study.

\subsection{Univariate Analysis of Influencing Factors for Antenatal Anxiety}

We examined relationships between demographic characteristics and antenatal anxiety. Significant differences in the prevalence of antenatal anxiety were found between groups with different characteristics, such as educational level, conjugal and family relationships, expected birth mode, pregnant-induced hypertension, sleep deprivation, and life satisfaction (Table 1). The prevalence of antenatal anxiety was higher among women with middle school or below degrees, women with 
disharmony in conjugal or family relationship. Furthermore, antenatal anxiety was more common among women expecting to give birth through natural delivery than those anticipating caesarean sections. Women with pregnancy-induced hypertension or lower life satisfaction had higher prevalence of antenatal anxiety.

\subsection{Multivariate Analysis of Influencing Factors for Antenatal Anxiety by Logistic Regression Model}

Variables were included into the bivariate logistic regression model if they had significant association $(p \leqslant 0.20)$ by the $\chi^{2}$ test or deemed important enough clinically despite no statistical significance. These variables included area, educational level, conjugal relationship, family relationship, expected birth mode, anemia before pregnancy, anemia during pregnancy, pregnancy-induced hypertension, sleep deprivation, morning sickness, and life satisfaction. After adjustment for socio-demographic characteristics (e.g., area, age, household income), the results of logistic regression analysis showed that antenatal anxiety was predicted significantly by lower education level, expected natural delivery, anemia during pregnancy, pregnancy-induced hypertension syndrome, and disharmony family relationship (Table 2).

Table 2. Logistic regression analysis for variables predicting antenatal anxiety symptoms.

\begin{tabular}{|c|c|c|c|c|}
\hline Variables & $\beta$ & Wald & $p$ Value & OR $(95 \% \mathrm{CI})$ \\
\hline College or Higher ${ }^{a}$ & -1.052 & 7.267 & 0.007 & $0.349(0.162-0.750)$ \\
\hline Harmony in the Family Relationship ${ }^{b}$ & -0.939 & 8.913 & 0.003 & $0.391(0.211-0.724)$ \\
\hline Anemia During Pregnancy & 0.870 & 5.686 & 0.017 & $2.387(1.17-4.878)$ \\
\hline Pregnancy-Induced Hypertension & 1.818 & 14.667 & $<0.001$ & $6.173(2.427-15.625)$ \\
\hline Expected Caesarean Sections ${ }^{c}$ & -0.799 & 8.802 & 0.003 & $0.450(0.265-0.762)$ \\
\hline Life Satisfaction & -1.744 & 29.617 & $<0.001$ & $0.175(0.093-0.328)$ \\
\hline
\end{tabular}

Results of multiple logistic regression analysis. Antenatal anxiety was the dependent variable; The selected factors were the independent variables. $\beta$ standardized partial regression coefficient. ${ }^{a}$ Middle school or below education level as reference or comparison group. ${ }^{b}$ Family relationship disharmony as reference or comparison group. ${ }^{\mathrm{C}}$ Expected natural delivery as reference or comparison group.

\section{Discussion}

Although obstetric intervention for physical care of pregnant women has improved dramatically in China over the past several decades, little attention has been paid to emotional care. This study is performed to assess the incidence of antenatal anxiety during pregnancy as well as associated risk factors in the Chinese population in mainland China.

This study finds that antenatal anxiety is prevalent in approximately one-fifth of the pregnant women in this study $(20.6 \%)$, which is consistent with a Brazilian study that found a high prevalence of antenatal anxiety [38]. In contrast, studies from developed Asian countries have reported a lower prevalence of such anxieties. For instance, a study on a sample of Singaporean women who were hospitalized during pregnancy shows that $12.5 \%$ of those women suffered from anxiety disorders [39]. Although socio-economic factors can cause anxiety, pregnancy could be an important alternative explanation. Most of the participants surveyed in our study were at least 38 weeks into their pregnancy, which is a point when they could deliver at any time. Therefore, it is likely that most of these women, who were in their third trimester, were experiencing a marked amount of physical discomfort, which could lead to anxiety [40]. Although the prevalence of estimated antenatal anxiety may vary significantly across different studies due to different sampling methodologies and measurement errors [41,42], these studies agree that anxiety is a common and significant problem during pregnancy and that antenatal anxiety has become an important public health issue, particularly in developing countries.

Moreover, our study shows that pregnancy-induced hypertension syndrome and anemia during pregnancy are the major risk factors of antenatal anxiety among pregnant women. However, to our knowledge, the literature on antenatal anxiety with pregnancy complication is limited. A previous 
research had shown that pregnant women in hospitals tended to become more anxious and vulnerable when they were in poor health [23], which is consistent with our study. Also, in another study, pregnant women with preeclampsia reported complete shock and tended to suffer from high anxiety due to fear of babies' prematurity, loss and guilt [43]. Therefore, pregnant women with complications should be given more psychological care from caregivers and their families, which could diminish the occurrence and development of antenatal anxiety.

Besides, this study has revealed that anxiety during pregnancy is associated with natural delivery method. To our surprise, our study found that planned cesarean deliveries, including those requested by the mother without medical reasons, were more common than planned natural deliveries (283 vs. 184). The fear of giving birth and experiencing a natural delivery is a real challenge for women, and this fear is strongly linked to the request for a cesarean section. Pang et al. found that women voluntarily elected cesarean sections after having their first child, even when they had attempted to give birth naturally in the past [37]. There are many unknown factors during pregnancy that cannot be controlled and that sometimes result in emergency cesarean deliveries, including situations involving intrauterine growth restriction, which eventually threatens the mother's or the baby's life. In addition, pregnant women are conscious during natural childbirth, are without the use of analgesics or anesthetics, and experience labor pain for at least a few hours. We suggest that these worries and fears contribute to the escalating prevalence of antenatal anxiety. According to Maier, for pregnant women, a planned cesarean section is a well-tolerated procedure, psychologically, when compared to natural childbirth [44]. Thus, as psychophysical care is an integral part of childbirth, professionals and caregivers need to pay close attention to women's psychological status in the management of pregnancy and labor pain.

Our study finds a statistically significant relation between disharmony in family relationship and anxiety, whereas, conjugal relationship is believed to be important for mental health disorders. However, the exact mechanism by which disharmony in family relationship affects anxiety remains unclear. We infer that a lack of social support is a possible factor that eventually influences help-seeking behaviors [45]. Some studies have found that people in lack of social support tend to suffer from mental illnesses than those with adequate social support. Pregnant women in absence of social support are apt to be pessimistic and suffer from low self-esteem or self-worth [46]. Interestingly, this is consistent with studies on paternal anxiety during pregnancy, which is due to low self-esteem and poor social support [47]. In particular, individuals in these surroundings of disharmony are less likely to seek useful support or help, suggesting the importance of social support during pregnancy, especially family care.

In our study, we also found that pregnant women with lower levels of education were at a higher risk for developing anxiety during pregnancy. Some other studies have also found this association between poor education and mental health [48]. A lower level of education is correlated with a lower socioeconomic status, and individuals with these qualities lack adequate resources and information to improve their situation during pregnancy. A job-education mismatch is believed to influence mental health [49]. In our study, although there was not a significant relationship between the participants' type of job and their anxiety level, we think education may have a stronger contribution to antenatal anxiety. Further, the results of our study indicate a significant association between life satisfaction and antenatal anxiety. In this respect, our findings highlight the importance of screening pregnant women dissatisfied with their lives so that the professional caregivers can provide more psychological care to the most vulnerable ones. In this way, we can recognize and decrease the incidence and the harmful consequences of antenatal anxiety effectively.

\section{Limitations}

Our study has the following limitations: First, because of limited resources and time constraints, we conducted the study in only one regional hospital in Changchun where the available sample group was small; thus, the results are not representative all of pregnant women in China. Secondly, 
gender preference, an important factor in the psychological health of pregnant Chinese women, and its influence on antenatal anxiety, could not be assessed in our study. Third, as a cross-sectional design study, we could not identify the change of anxiety throughout pregnancy, and finally, this study was not designed to study the relationship between anxiety and depression during pregnancy, nor its impact on psychological health in postpartum period.

\section{Conclusions}

Our study has shown that pregnancy-induced hypertension syndrome, anemia during pregnancy, lower degree of education, expected natural delivery, and life dissatisfaction are the main risk factors of antenatal anxiety among pregnant women. Thus, it is important to identify women at risk and to reduce antenatal anxiety occurring by improving the health status of pregnant women and strengthening prenatal related education and mental health intervention.

Acknowledgments: Our study is funded by The National Natural Science Foundation (81102163). The authors acknowledge the support of Changchun Maternity Hospital, Jilin, China and participants. We wish to thank Rajesh Kumar Shah for help with the English language in the manuscript.

Author Contributions: All authors contributed to this manuscript. Bo Li and Yan Yao conceived and designed the experiments; Jing Dou, Shu-yue Li and Hong-zhi Han performed the experiments, Cai-ning Zhao analyzed the data and wrote most of the introduction, Xin Guo, Yu-ting Kang and Yan Yao wrote most of the paper.

Conflicts of Interest: The authors declare no conflict of interest.

\section{Abbreviations}

The following abbreviations are used in this manuscript:

SAS the Self-Rating Anxiety Scale

HPA hypothalamic-pituitary-adrenal

SWLS the Satisfaction With Life Scale

\section{References}

1. Niloufer, S.A.; Iqbal, S.A.; Badar, S.A.; Ghurnata, T.; Sana, S. Frequency and associated factors for anxiety and depression in pregnant women: A hospital-based cross-sectional study. Sci. World J. 2012, 2012, 1-9.

2. Meades, R.; Ayers, S. Anxiety measures validated in perinatal populations: A systematic review. J. Affect. Disord. 2011, 133, 1-15. [CrossRef] [PubMed]

3. Fatma, Y.; Semiha, A.; Zehra, D. Prenatal distress in Turkish pregnant women and factors associated with maternal prenatal distress. J. Clin. Nurs. 2014, 23, 54-64.

4. Edwar, D.B.; Barbara, M. Differentiating early-onset persistent versus childhood-limited conduct problem youth. Am. J. Psychiatry 2009, 166, 900-908.

5. Ding, X.X.; Wu, Y.L.; Xu, S.J.; Zhu, R.P.; Jia, X.M.; Zhang, S.F.; Huang, K.; Zhu, P.; Hao, J.H.; Tao, F.B. Maternal anxiety during pregnancy and adverse birth outcomes: A systematic review and meta-analysis of prospective cohort studies. J. Affect. Disord. 2014, 159, 103-110. [CrossRef] [PubMed]

6. Giuseppe, M.; Paola, S.; Maria, R.G.; Daniele, D.; Filippo, B.; Tullia, T. Impact of maternal psychological distress on fetal weight, prematurity and intrauterine growth retardation. J. Affect. Disord. 2008, 111, $214-220$.

7. Hashima, E.N.; Zarina, K.; Yvonne, F.; Maigun, E. Low birth weight in offspring of women with depressive and anxiety symptoms during pregnancy: Results from a population based study in Bangladesh. BMC Public Health 2010, 10, 515.

8. Chang, M.Y.; Chen, C.H.; Huang, K.F. Effects of music therapy on psychological health of women during pregnancy. J. Clin. Nurs. 2008, 17, 2580-2587. [CrossRef] [PubMed]

9. Vivette, G.; Kristin, B.; Pampa, S.; Thomas, G.O. Association between maternal and amniotic fluid cortisol is moderated by maternal anxiety. Psychoneuroendocrinology 2009, 34, 430-435.

10. Thomas, G.O.; Jonathon, H.; Jean, G.; Michael, B.; Vivette, G. Maternal antenatal anxiety and children's behavioural/emotional problems at 4 years. Report from the Avon Longitudinal Study of Parents and Children. Br. J. Psychiatry 2002, 180, 502-508. 
11. Thomas, G.O.; Jonathon, H.; Vivette, G. Antenatal anxiety predicts child behavioral/emotional problems independently of postnatal depression. J. Am. Acad. Child. Adolesc. Psychiatry 2002, 41, 1470-1477.

12. Rice, F.; Harold, G.T.; Boivin, J.; van den Bree, M.; Hay, D.F.; Thapar, A. The links between prenatal stress and offspring development and psychopathology: Disentangling environmental and inherited influences. Psychol. Med. 2010, 40, 335-345. [CrossRef] [PubMed]

13. Anjanette, P.H.; Jonathon, S. Glucocorticoids, prenatal stress and the programming of disease. Horm. Behav. 2011, 59, 279-289.

14. Martin, K.; Diana, A.; Brida, C.; Vivette, G. Pregnant women become insensitive to cold stress. BMC Preg. Childbirth 2002, 2, 8.

15. Jonathan, H.; Thomas, G.O.; Jonathan, E.; Jean, G.; Vivette, G. The course of anxiety and depression through pregnancy and the postpartum in a community sample. J. Affect. Disord. 2004, 80, 65-73.

16. Kessler, R.C.; Laura, H.S.A.; Bijl, R.V.; Offord, D.R.; Olga, D.; Dan, J.S. The effects of co-morbidity on the onset and persistence of generalized anxiety disorder in the ICPE surveys. International Consortium in Psychiatric Epidemiology. Psychol. Med. 2002, 32, 1213-1225. [CrossRef] [PubMed]

17. Robert, C.S.; Eric, U.; Barbara, T.; Francis, C. A cross-sectional study of antenatal depression and associated factors in Malawi. Arch. Womens Ment. Health 2014, 17, 145-154.

18. Asher, I.; Kaplan, B.; Fau-Modai, I.; Modai, I.; Fau-Neri, A.; Neri, A.F.A.; Valevski, A.F.A.; Weizman, A. Mood and hormonal changes during late pregnancy and puerperium. Clin. Exp. Obstet. Gyn. 1995, 22, 321-325.

19. Antoinette, M.L.; Siu, K.L.; Stepphanie, S.M.L.; Catherine, S.Y.C.; Ada, C.; Daniel, Y.T.F. Prevalence, course, and risk factors for antenatal anxiety and depression. Obstet. Gyn. 2007, 110, 1102-1112.

20. Hashima, E.N.; Zarina, K.; Yvonne, F.; Maigun, E. Prevalence and associated factors of depressive and anxiety symptoms during pregnancy: A population based study in rural Bangladesh. BMC Womens Health 2011, 11, 22.

21. Ri-hua, X.; Guoping, H.; Aizhong, L.; Jacques, B.; Mark, W.; Shi, W.W. Fetal gender and postpartum depression in a cohort of Chinese women. Soc. Sci. Med. 2007, 65, 680-684.

22. Wing, C.; Wan-Yim, I.; Dominic, S.K.C. Maternal anxiety and feelings of control during labour: A study of Chinese first-time pregnant women. Midwifery 2007, 23, 123-130.

23. Carol, C.B.; Nicola, J.S. Predictors of anxiety among pregnant New Zealand women hospitalised for complications and a community comparison group. Midwifery 2015, 31, 888-896.

24. Mohd, A.F.; Kartini, B.; Rosdinom, R.; Hatta, S.; Thinakaran, M.; Robert, P.J.; Marhani, M.; Nik, R.N.J.; Srijit, D.; Mohd, R.A.M. Risk factors for depression and anxiety among pregnant women in Hospital Tuanku Bainun, Ipoh, Malaysia. Asia Pac. Psychiatry 2013, 5 (Suppl. S1), 7-13.

25. César, T.; Bárbara, F.; Ana, C.; Alexandra, P.; Raquel, C. Anxiety and depression during pregnancy in women and men. J. Affect. Disord. 2009, 119, 142-148.

26. Lau, Y. The effect of maternal stress and health-related quality of life on birth outcomes among Macao Chinese pregnant women. J. Perinat Neonatal Nurs. 2013, 27, 14-24. [CrossRef] [PubMed]

27. O'Hara, M.; Wisner, K. Perinatal mental illness: Definition, description and aetiology. Best Pract. Res. Clin. Obstet. Gyn. 2014, 28, 3-12. [CrossRef] [PubMed]

28. Kaplan, S.C.; Levinson, C.A.; Rodebaugh, T.L.; Menatti, A.; Weeks, J.W. Social anxiety and the Big Five personality traits: The interactive relationship of trust and openness. Cogn. Behav. Ther. 2015, 44, $212-222$. [CrossRef] [PubMed]

29. Tan, P.C.; Zaodi, S.N.; Azmi, N.; Omar, S.Z.; Khong, S.Y. Depression, anxiety, stress and hyperemesis gravidarum: Temporal and case controlled correlates. PLoS ONE 2014, 9, e92036. [CrossRef] [PubMed]

30. Samakouri, M.; Bouhos, G.; Kadoglou, M.; Giantzelidou, A.; Tsolaki, K.; Livaditis, M. Standardization of the Greek version of Zung's Self-rating Anxiety Scale (SAS). Psychiatriki 2012, 23, 212-220. [PubMed]

31. Wang, Z. Chinese version of Zung's self-rating anxiety scale. J. Shanghai Psychiatry 1984, 2, 73-74.

32. Pavot, W.; Diene, E.; Colvin, R.; Sandvik, E. Further validation of the satisfaction with life scale: Evidence for the cross-methods convergence of well-being measures. J. Pers. Assess. 1991, 57, 149-161. [CrossRef] [PubMed]

33. Pavot, W.; Diener, E.; Suh, E. The temporal satisfaction with life scale. J. Pers. Assess. 1998, 70, 340-354. [CrossRef] 
34. Grace, W.L.C.; Gabor, S.U.; Daniel, T.L.S.; John, J.P.L. Hospital and community-based care for patients with chronic schizophrenia in Hong Kong-Quality of life and its correlates. Soc. Psychiatry Psychiatr. Epidemiol. 2003, 38, 196-203.

35. Pavot, W.; Diener, E. The satisfaction with life scale and the emerging construct of life satisfaction. J. Posit. Psychol. 2008, 3, 137-152. [CrossRef]

36. Ilkay, G.; Umran, Y.O.; Nezihe, K.B. Biopsychosocial risk factors for preterm birth and postpartum emotional well-being: A case-control study on Turkish women without chronic illnesses. J. Clin. Nurs. 2011, 20, 653-665.

37. Pang, M.W.; Leung, T.N.; Lau, T.K.; Chung, T.K.H. Impact of first childbirth on changes in women's preference for mode of delivery: Follow-up of a longitudinal observational study. Birth 2008, 35, 121-128. [CrossRef] [PubMed]

38. Caroline, R.F.; Mayara, C.O.; Camilla, R.V.; Andrea, M.A.P.; Roberta, R.S. Prevalence of anxiety symptoms and depression in the third gestational trimester. Arch. Gyn. Obstet. 2015, 291, 999-1003.

39. Thiagayson, P.; Krishnaswamy, G.; Lim, M.L.; Sung, S.C.; Haley, C.L.; Funf, D.S.S.; Allen, J.C.; Chen, H. Depression and anxiety in Singaporean high-risk pregnancies-prevalence and screening. Gen. Hosp. Psychiatry 2013, 35, 112-117. [CrossRef] [PubMed]

40. Costa, D.D.; Larouche, L.; Dritsa, M.; Brender, W. Variations in stress levels over the course of pregnancy: Factors associated with elevated hassles, state anxiety and pregnancy-specific stress. J. Psychosom. Res. 1999, 47, 609-621. [CrossRef]

41. Janice, H.G.; Kerry, L.C.; Marlene, P.F. Anxiety disorders during pregnancy: A systematic review. J. Clin. Psychiatry 2014, 75, e1153-e1184.

42. Mark, H.R. Transcultural issues in mood and anxiety disorders: A focus on Japan. CNS Spectrums 2004, 9, 6-13.

43. Christine, E.; Kathleen, C.; Wendy, P.; Natasha, F.; Shaun, B. Women's experiences of preeclampsia: Australian action on preeclampsia survey of women and their confidants. J. Pregnancy 2011. [CrossRef]

44. Maier, B. Women's worries about childbirth: Making safe choices. Br. J. Midwifery 2010, 18, $293-299$. [CrossRef]

45. Zachariah, R. Social support, life stress, and anxiety as predictors of pregnancy complications in low-income women. Res. Nurs. Health 2009, 32, 391-404. [CrossRef] [PubMed]

46. Adriana, J.U.; Am, B.G.; Kimberly, A.U.; Laudan, B.G. A longitudinal examination of support, self-esteem, and Mexican-origin adolescent mothers' parenting efficacy. J. Marriage Fam. 2013, 75, 746-759.

47. Koh, Y.W.; Lee, A.M.; Chan, C.Y.; Fong, D.Y.; Lee, C.P.; Leung, K.Y.; Tang, C.S. Survey on examining prevalence of paternal anxiety and its risk factors in perinatal period in Hong Kong: A longitudinal study. BMC Public Health 2015, 15, 1131. [CrossRef] [PubMed]

48. Araya, R.; Rojas, G.; Fritsch, R.; Acuna, J.; Lewis, G. Santiago mental disorders survey: Prevalence and risk factors. Br. J. Psychiatry 2001, 178, 228-233. [CrossRef] [PubMed]

49. Bracke, P.; Van, S.V.; Missinne, S. Education, mental health, and education-labor market misfit. Health Soc. Behav. 2014, 55, 442-459. [CrossRef] [PubMed]

(C) 2016 by the authors; licensee MDPI, Basel, Switzerland. This article is an open access article distributed under the terms and conditions of the Creative Commons Attribution (CC-BY) license (http://creativecommons.org/licenses/by/4.0/). 